\title{
The Potential of Agritourism in Revitalizing Rural Communities: Some Empirical Results
}

\author{
Salvatore Ammirato and Alberto Michele Felicetti \\ Department of Mechanical Energy and Management Engineering, University of Calabria \\ via P. Bucci, 42lC, 87036 Rende (CS), Italy \\ \{salvatore.ammirato, alberto.felicetti\}@unical.it
}

\begin{abstract}
Modern patterns of rural development propose a rational and respectful exploitation of agricultural resources together with the rediscovery of historical and naturalistic heritage as means to reach sustainable development. In this sense, Agritourism represents the contact point between the tourists' request of wellbeing, genuineness and rediscovery of nature, and the offer of typical agricultural products and touristic services of a network of rural organizations. The aim of this study is to improve our understanding of how agritourism activities can contribute to revitalize rural communities; the study assumes particular importance in a period of economic crisis characterized by the failure of the traditional patterns of rural development. We present key findings of an explorative survey carried out in the Calabria region, Italy, during 2012 on a sample of 52 farms offering agritourism activities. The study deploys an original methodology aimed to highlight the extent of the agritourism phenomena in the selected region and to evaluate how agritourism can support sustainable development of a rural community becoming the hub of an "agritourism rural network".
\end{abstract}

Keywords: Agritourism, rural network, agritourism rural network, rural community, sustainability, Calabria.

\section{Introduction}

The question of rural development has been long addressed by the scientific community [1][2]. Rural development can be defined in general terms as "an overall increase in the welfare of the residents of rural areas and, more generally, as the contribution that rural resources offer to the welfare of the entire rural population" [3]. The concept of rural development is becoming increasingly complex, going beyond the boundaries of the economic sphere and leading to a growing emphasis on the not overexploitation of natural resources and landscape, as well as on the rediscovery and valorization of existing tangible (infrastructure, monuments, typical foods, etc...) and intangible assets (culture heritage, traditions, history). Scholars group such patterns into the concept of "sustainable development", asserting the importance to involve local actors in common development pathways [4] [5].

In the effort to gain sustainable development, farmers and other organizations have started organizing themselves spontaneously in rural networks in order to solve their 
problems and those of rural communities. New and alternative business models have developed with the aim to guarantee competitive advantages, to improve farm revenue streams, to return in taking an active role in the agrifood system, and to develop new consumer market niches [6]. Such models are known as Alternative AgriFood Networks, AAFNs [7], which are collaborative networks in the agrifood sector characterized by a re-connection among producers and consumers with these explicit ethical and political goals: "re-vitalisation of territory identity and rural community relations to local food and agriculture, linking with sustainable agriculture, economically viable and socially responsible practices" [8].

In this work we aim to deepen the understanding of the Agritourism phenomenon and evaluate its potential as a model for the sustainable development of rural communities. In details, the paper is organized as follows. In section 2 the theoretical background of the study is summarized in order to have a fully understanding of the survey whose methodology is reported in section 3. Survey results and discussion are present in section 4 followed by conclusion in section 5 .

\section{Theoretical Background}

In the last decades, rural communities have been invested from deep changes consisting mainly in the shift of economic activities and population to urban areas and in the loss of significance of the agricultural sector as the most important sector in terms of production, wealth and number of employees. These phenomena brought a crisis in traditional structure and organization of rural areas, exposing them to the risk of a economic, social and environmental decline, that involved agricultural sector as well as the entire local economy and rural communities as a whole [9] [10]. From the producers side, farmers are continuously looking for "new ways" of doing business, exploring the viability of alternative economic strategies [11]. According to [12], the main questions for farmers still remains "How, why, to what extent and under what conditions can the combination of activities within a rural enterprise positively affect costs, benefits, risks and prospects?".

From the consumers side, the increasing demands for quality safe, healthy and ethically correct food, led to a widening consensus that conventional agriculture is no more sustainable and radical changes are needed [13]. New organizational networks, based on processes of synergic collaboration, between farmers, consumers and other rural actors emerged in recent years in order to propose solutions for the rural community question [5][8][14][15]. Problems are better understood when analysed from different perspectives, thus a collection of differently skilled actors can, in principle, go beyond individual knowledge and reach new solutions for the whole community's questions [16][17][18][19]. Various studies [20][21], state that farmers might be able to realize their expectations by shortening long and complex agrifood supply chains and by embedding high "typical and quality" features, strictly linked to local agrifood products, within their production processes. AAFNs give farmers a direct means to increase their revenues by reducing intermediaries along the supply chain as well as the opportunity to strengthen relationship with consumers, by offering "personal" quality guarantees on products [11] [20]. AAFN paradigm is strictly interconnected with relocalization principles which are seen as a way to 
reinvigorate rural communities, reducing producers' dependence on subsidies and increase agricultural competitiveness [22]. Relocalization is characterized by the rediscovery of local traditions and environmental and cultural heritage as means of improving well-being, authenticity, and, in a more general sense, quality of life. Rural communities development concept goes beyond the boundaries of the economic sphere and leads to a growing emphasis on the exploitation of natural resources and landscape, as well as a rediscovery of tangible and intangible resources. In this sense, rural communities can look at "tourism" as an opportunity to diversify the economy and revitalize rural areas [23] [24].

\subsection{Agritourism and Rural Networks}

From an organizational point of view, a rural community is characterized by different autonomous entities (people and organization) that live and operate in a rural area, i.e. areas with poor infrastructure, far from major urban areas, and characterized by economic and cultural backwardness [10]. These entities aim to achieve the common goal of sustainable local development in order to increase their general competitiveness in a larger area. A rural community can be viewed as a Breeding Environment, BE [25], characterized by shared principles, infrastructures and culture, where networking and cooperation is practiced among their members. Within a rural community it is possible to identify particular kinds of Collaborative Networks [26], the Rural Networks, which are particular AAFNs whose members are not only agrifood producers, but also suppliers of touristic service, craftsmen, artists, local public administrations, etc. who want exploit advantages of AAFNs and relocalization offering tourists to experience rural tourism while tasting/buying local agrifood products. Members of a rural network are a subset of the rural community actors that establish long term and structured collaboration relationships and align their actions, interests, resources and goals, in order exploit business opportunities arising from direct and not-mediated connections with customers. In this paper we introduce the concept of Agritourism Rural Network considering agritourism as a farm activity able to give sustainable development to rural communities. Agritourism farm represents the hub of a rural network, the place where agrifood products and tourism services meet consumers demand for relocalization, the trigger to motivate further direct business opportunities between tourists and other rural community actors.

Agritourism is a widely debated topic in the scientific literature. According to the Italian legislative system, which acknowledges the European Union directives, the agritourism is exclusively defined as "tourism activities exercised by farmers through the exploitation of their own farm according to a logic of "connection", "complementarity" and "non-prevalence"[27]. In the scientific literature the term "agritourism" is often understood in a wide sense as a synonym for "farm tourism", "farm-based tourism", and "rural tourism. All these definitions present a common point in the rural/agricultural context in which services are provided [28] [29]. Many authors utilize the term "working farm" where tourism services are provided besides traditional agricultural activities. In our intent, rural tourism refers simply to tourism services provided in a rural context, while agritourism refers to "tourism services provided by agricultural entrepreneurs within their own farm, allowing also visitors to take part, directly or indirectly, in agricultural activities" [30]. In particular, 
agritourism farm may offer services as hospitality, meal provision, farm tour, on-site processing of agricultural goods, pick-your-own activities and so on. In [31] authors emphasize the dual role of agritourism for both individual "actors" (rural tourism operators, intermediaries in the tourism sector and visitors) and rural community as a whole. In fact, agritourism farms serve as a stimulus for other local activities (agrifood producers, crafts, restaurants, shops), as well as contributing to the preservation of customs and the local culture [32]. In those rural communities where members actively collaborate with farmers in their arrangement of agritourism services provision, we can observe the rise of an agritourism rural network.

\section{The Survey}

In this section we propose some results of an exploratory survey conducted among farms of a rural region with the aim to understand if and how farmers and rural actors, exploit agritourism potentials as a means to revitalize the rural community. Moreover, we aim to highlight the presence of agritourism rural networks in the surveyed region where rural actors operate together with agritourism farms for the sustainable development of the rural community.

\subsection{Research Questions}

The research questions can be defined as follow:

RQ1: Do farmers understand the importance of setting agritourism activities within their farm?

RQ2: Can the agritourism farm be a direct contact point between the rural community offer of products/services and the tourist request for relocalization?

- Do farmers offer tourists possibilities to enjoy the cultural and/or naturalistic heritage of the region? When such possibilities are offered, do tourists enjoy them?

- Do farmers offer tourists possibilities to taste and buy typical local agrifood products of the region? When such possibilities are offered, do tourists enjoy them?

RQ3: Is it possible to highlight the presence of an agritourism rural network in supporting the activities of the agritourism farm?

- In their products and services offer, do farmers act in formal cooperation with other suppliers of the rural networks?

- Which is the percentage of products or services sold through the agritourism farm that is supplied by local firms/associations?

- Are there any long-term supply contracts with such firms/associations?

- How many local workers are engaged by the farm exclusively to carry out the agritourism activities?

\subsection{Methodology}

The methodology is designed to address the research questions and can be applied to all regions being studied. The methodology is made up of the following steps: 
$\underline{\text { step 1: }}$ : determine the overall number of agribusiness in the region, and how many of them are officially authorized to offer an agritourism experience and are currently active. The set of such agritourism farms constitutes the population of interest for our analysis.

step 2: Definition of a questionnaire to be delivered to the managers of the agritourism farms within the population of interest. Responses to the questionnaire will be analyzed to answer the research questions.

step 3: Delivery of the questionnaire to the farms' managers and gathering of their filled forms. The set of agritourism farms whose managers filled the questionnaire constitutes the sample of the analysis.

step 4: Analysis of the managers' responses of the sample in order to answer the research questions and discussion.

\section{Survey Results and Discussion}

The proposed methodology has been applied to the agritourism farms located in the Calabria region (Italy) and has been carried out from 01 October 2012 to 31 December 2012. Calabria is a "lagging behind region" (i.e., a European Union region with per capita GDP, measured in purchasing power parties, less than $75 \%$ of the Community average [10]) with a population density of less than 150 inhabitants per square kilometers and whose endemic problems are broadly characterized by geographical remoteness, low population density, low income levels, limited employment opportunities, dependency on agriculture, poor service provision, and poor development capacities [33].

In line with step 1 of the methodology, the population of interest, $P$, of our analysis was selected using an official agritourism database directly purchased from the Italian Chambers of Commerce. The "Regional agritourism farms registry" at the office of the Regional Department of Agriculture was used as a cross reference to validate the selections. We surveyed that the number of Calabrian farms offering some forms of agritourism experience is rapidly increasing in few years; the number of new authorized agritourism activities in the period 2005-2010 presented a grow rate of $56 \%$ (from 313 to 488 ) while the Italian national rate was $26 \%$ in the same period (from 15.327 to 19.304) [31]. In particular, at the end of 2010, on 137.790 agribusinesses present in Calabria, only $488(0.35 \%)(0.26 \%$ in 2005) were authorized and active in agritourism; so $P$ is made up of 488 agritourism farms [31].

According to step 2, a questionnaire was set up containing 10 questions, all designed to answer the research questions. For each farms belonging to $\mathrm{P}$, we tried to have a phone meeting with the managers in order to deliver the questionnaire. On 488 agritourism farms in P, 52 of them , the 10.6\%, agreed to answer the questionnaire. After a telephonic interview with the farm managers, we gathered their responses; at the end of step 3 the final sample was made up of 52 farms. According to step 4, for each of the farms in the sample, we analyzed the gathered responses and statistical results of the analysis are reported in the next section.

To answer RQ1, we can put in contrast quantitative results from official statistical data and qualitative results from our survey. First data point out that few are the 
Agritourism farms in Calabria (488), especially in relative terms on the overall number of agribusiness activities in the region $(0.35 \%)$ and to analogous rates in other Italian regions (4.2\% of Tuscany's farms and $11.27 \%$ of Trentino Alto Adige's farms) [31]. Looking at the statistical analysis of questionnaires in the sample, $38 \%$ of respondents affirmed that over half of the overall farm's yearly turnover come from the agritourism activities, while $29 \%$ declared that the rate of turnover coming from agritourism activities is between $20 \%$ and $50 \%$. Overall, $67 \%$ of respondents declared that more than $20 \%$ of the farm's yearly turnover come from agritourism activities. Looking at the costs side, $21 \%$ of respondents declared that more than $50 \%$ of the farm's costs come from the agritourism activities, while $23 \%$ declared that the rate of costs ascribed to the agritourism activities is between $20 \%$ and $50 \%$. Overall, $44 \%$ of respondents stated that the rate of total agribusiness costs ascribed to the agritourism activities is more than $20 \%$. Moreover, $51 \%$ of respondents affirm the will to increase the investments in the agritourism activities in the following year, with respect to the previous year, while only $8 \%$ of them want to reduce the investments.

The small number of agritourism farms present in Calabria, suggests that we cannot positively answer to RQ1. Anyway, the rapid increase of the new authorized agritourism activities in the last few years $(+56 \%$ in the period $2005-2010)$ point out that the awareness about the importance of setting an agritourism activity within the farm is spreading among farmers of the regions. Such awareness is strengthened by statistical data from the survey which highlight the economical positive results reported by agribusiness where agritourism activities are present and the generalized will of sampled agribusiness to continue invest and, in many cases, to increase the investments. Positive feedback stated from the surveyed farms can be an important reason to motivate other farmers in doing the same and it can help to explain the rapid growth rate of new authorized activities in Calabria.

To answer RQ2, we identify some activities that let tourists enjoy the cultural and/or naturalistic heritage of the region as well as taste and/or buy typical agrifood products of the region. For each activity, we asked respondents to state if such activity was present in their agritourism offer and, in case of positive answer, to indicate the percentage of their customers who purchased /enjoyed it in the previous year. Results from the statistical analysis point out that surveyed farms intend agritourism mainly as a means to:

- let tourists enjoy services within the property of the farm (overnight accommodation offered by $84,62 \%$ of respondents and purchased by $34,58 \%$ of their customers, and educational farm, offered by $44,23 \%$ of respondents and purchased by $19 \%$ of their customers) or, at the most, visits to touristic places at free entrance (offered by $51,92 \%$ of respondents and enjoyed by $45,28 \%$ of their customers);

- taste/buy/cook self-produced food (offered by 65,38\% / 71,15\% / 94,23\% of respondents, enjoyed by, respectively, 55\% / 17\% / 84,63\% of their customers).

So we cannot give positive answer to RQ2, highlighting that agritourism is still intended by farmers only as a means to sell products/services self-produced. At the same time, the rural community is not able to exploit the presence of agritourism farms as direct contacts point with the tourists intended as potential customers. 
To answer RQ3, is important to note that statistical analysis of responses in the sample point out that:

- $40 \%$ of respondents declared they have some kinds of formal cooperation with other actors of the rural network

- $12 \%$ of respondents declared that more than $20 \%$ of the agrifood products utilized in their agritourism activities come from other actors of the rural network; $61 \%$ stated that less than $20 \%$ of the agrifood products they utilized in their agritourism farms come from other local actors. Only $27 \%$ stated they utilized only agrifood products self-produced. Overall, $71 \%$ of respondents utilize products supplied from the rural network.

- $67 \%$ of respondents who utilize products supplied from the rural network, affirmed to have long-term and stable supply contracts with the other actors of the rural networks;

- on average, almost 5 local workers are engaged by the farm exclusively to carry out the agritourism activities.

Data show the emergence of real agritourism rural networks in Calabria. Rural community benefits from the agritourism presence mainly for agrifood producers, which receive direct benefits from long-term contract, and local workers, who are directly engaged for the agritourism services offered to tourists. Less diffused are connections with non-food producers local partners.

\section{Conclusions}

Agritourism activities, even if not so diffused among Calabrian farms, give farmers important revenues being an alternative way for selling farms' products and services. The reason because rural community does not fully exploit benefits from direct connections with agritourism customers remains unclear: is the community that cannot understand potentials of this connection or is it a lack of entrepreneurial farsightedness among agritourism farmers? Yet, direct contacts between agritourists and rural community actors can benefit both the agritourism farm and the rural community.

Anyway, stable rural networks exist within the orbit of the Calabrian agritourism farms. Data analysis picture the most diffused agritourism rural network model in Calabria as so characterized:

- the agritourism farm represents the rural network hub, the contact point between rural network offer and tourists/customers demand.

- Local suppliers, through their long-term contracts with the farm, offer agritourists their goods and services having an indirect contact with them (mediated by the farm). Such provisions contributes to enrich and complete the basket of rural offer to the tourists.

- Local workers benefit from employment opportunities at the farm site.

Even if this survey is the first of its kind, results are encouraging in supporting our hunches about the importance of setting agritourism activities, both for farms and for the rural community, as a means to revitalize the rural communities. 


\section{References}

1. Leon, Y.: Rural development in Europe: a research frontier for agricultural economists. European Review of Agricultural Economics (2005)

2. Murdoch, J.: Networks - a new paradigm of rural development? Journal of Rural Studies 16(4), 407-419 (2000)

3. Hodge, I.D.: The scope and context of rural development. European Review of Agricultural Economics 13(3), 271-282 (1986)

4. Allen, P., Van Dusen, D., Lundy, J., Gliessman, S.: Integrating social, environmental, and economic issues in sustainable agriculture. American Journal of Alternative Agriculture 6(1), 34-39 (1991)

5. Ammirato, S., Felicetti, A.M.: Tourism Breeding Environment: Forms and Levels of Collaboration in the Tourism Sector. In: Camarinha-Matos, L.M., Scherer, R.J. (eds.) PRO-VE 2013. IFIP AICT, vol. 408, pp. 517-524. Springer, Heidelberg (2013)

6. Volpentesta, A.P., Ammirato, S.: Networking agrifood SMEs and consumer groups in local agribusiness. In: Camarinha-Matos, L.M., Picard, W. (eds.) Pervasive Collaborative Networks. IFIP, vol. 283, pp. 33-40. Springer, Boston (2008)

7. Volpentesta, A.P., Ammirato, S., Della Gala, M.: Knowledge exchange and social learning opportunities in direct agri-food chains. In: Camarinha-Matos, L.M., Xu, L., Afsarmanesh, H. (eds.) PRO-VE 2012. IFIP AICT, vol. 380, pp. 340-348. Springer, Heidelberg (2012)

8. Volpentesta, A.P., Ammirato, S.: Alternative Agrifood Networks in a regional area: a case study. The International Journal of Computer Integrated Manufacturing 26(1-2), 55-66 (2013)

9. Volpentesta, A.P., Ammirato, S.: Enabling Virtual Organizations in a Technological District. In: Camarinha-Matos, L.M., Afsarmanesh, H., Novais, P., Analide, C. (eds.) Establishing the Foundation of Collaborative Networks. IFIP, vol. 243, pp. 103-110. Springer, Boston (2007)

10. Ilbery, B., Maye, D., Knafsey, M.: Forecasting supply chain developments in lagging rural regions. Journal of Rural Studies 20, 331-344 (2004)

11. McGehee, N.G., Kyungmi, K.: Motivation for agri-tourism entrepreneurship. Journal of Travel Research 43, 161-170 (2004)

12. Van der Ploeg, J.D., Long, A., Banks, J.: Rural development: The state of the art. In: Van der Ploeg, J.D., Long, A., Banks, J. (eds.) Living Countrysides. Rural Development Processes in Europe: The State of the Art, pp. 8-17. Elsevier, Amsterdam (2002)

13. Watts, D.C.H., Ilbery, B., Maye, D.: Making Alternative systems of food provision. Progress in Human Geography 29(1), 22-40 (2005)

14. Volpentesta, A.P., Ammirato, S.: A Collaborative Network Model for Agrifood Transactions on Regional Base. In: Lytras, M.D., Ordonez de Pablos, P., Ziderman, A., Roulstone, A., Maurer, H., Imber, J.B. (eds.) WSKS 2010. CCIS, vol. 112, pp. 319-325. Springer, Heidelberg (2010)

15. Corvello, V., Iazzolino, G., Ritrovato, V.: Evaluating technological innovations: A method based on comparable transactions, European Journal of Economics. Finance and Administrative Sciences 56, 37-50 (2013)

16. Volpentesta, A.P., Ammirato, S., Sofo, F.: Collaborative design learning and thinking style awareness. The International Journal of Engineering Education 28(4), 948-958 (2012)

17. Volpentesta, A.P., Ammirato, S., Sofo, F.: Thinking style diversity and collaborative design learning. In: Camarinha-Matos, L.M., Paraskakis, I., Afsarmanesh, H. (eds.) PRO-VE 2009. IFIP AICT, vol. 307, pp. 785-796. Springer, Heidelberg (2009) 
18. Sofo, F., Ammirato, S.: Establishing a Learning Culture: the Importance of Relationships within an Organization. In: Lytras, M.D., Ruan, D., Tennyson, R.D., Ordonez De Pablos, P., García Peñalvo, F.J., Rusu, L. (eds.) WSKS 2011. CCIS, vol. 278, pp. 271-277. Springer, Heidelberg (2013)

19. Sofo, F., Berzins, M., Colapinto, C., Ammirato, S.: North, south, least, best: Geographical location and the thinking styles of Italian university students. Australian Journal of Adult Learning 49(2), 269-291 (2009)

20. Higgins, V., Dibden, J., Cocklin, C.: Building alternative agrifood networks: Certification, embeddedness and agrienvironmental governance. Journal of Rural Studies, 15-27 (2008)

21. Volpentesta, A.P., Ammirato, S.: Evaluating e-commerce web interfaces of agri-food SMEs in an European lagging behind region. International Journal of Entrepreneurship and Innovation Management 7(1), 74-91 (2007)

22. Clemens, R.: Keeping farmers on the land: Adding value in agriculture in the Veneto Region of Italy (MATRIC Briefing Paper 04-MBP 8). Midwest Agribusiness Trade Research and Information Center. Iowa State University, USA (2004)

23. Weaver, D.B., Fennell, D.A.: The vacation farm sector in Saskatchewan: A profile of operations. Tourism Management 18(6), 357-365 (1997)

24. Rotheram, I.D.: Emerging concepts and Case Studies of Eco-cultural Tourism. In: Raj, R., Griffin, K.A., Morpeth, N.D. (eds.) Cultural Tourism, CAB International (2013)

25. Camarinha-Matos, L.M., Afsarmanesh, H., Boucher, X.: The role of collaborative networks in sustainability. In: Camarinha-Matos, L.M., Boucher, X., Afsarmanesh, H. (eds.) PRO-VE 2010. IFIP AICT, vol. 336, pp. 1-16. Springer, Heidelberg (2010)

26. Ammirato, S., Della Gala, M., Volpentesta, A.P.: Alternative Agrifood Networks as Learning Communities: Some Issues for a Classification model. In: Lytras, M.D., Ruan, D., Tennyson, R.D., Ordonez De Pablos, P., García Peñalvo, F.J., Rusu, L., et al. (eds.) WSKS 2011. CCIS, vol. 278, pp. 293-300. Springer, Heidelberg (2013)

27. LEGGE 20 FEBBRAIO, n. 96 "Disciplina dell'agriturismo" (2006)

28. Karabati, S., Dogan, E., Pinar, M., Celik, L.M.: Socio-Economic Effects of Agri-Tourism on Local Communities in Turkey: The Case of Aglasun. International Journal of Hospitality \& Tourism Administration 10(2), 129-142 (2009)

29. Marques, H.: Searching for complementarities between agriculture and tourism. Tourism Economics 12, 147-155 (2006)

30. Phillip, S., Hunter, C., Blackstock, K.: A typology for defining agritourism. Tourism Management 31, 754-758 (2010)

31. McGehee, N.G.: An Agritourism Systems Model: A Weberian Perspective. Journal of Sustainable Tourism 15(2), 111-124 (2007)

32. Wilson, J., Thilmay, D., Watson, P.: The role of agritourism in Western states: place specific and policy factors influencing recreational income for producers. Review of Regional Studies 36(3), 381-399 (2006)

33. ISTAT, Sixth General Census of Agriculture in Italy (2013) 